Except for the field of herbal medicine, women by and large contributed to the diffusion of botanical knowledge rather than to its creation. They did not devise taxonomies, classifying the bounty of nature, nor did they set the agenda for botanical sciences, establishing for future generations what was to be known and not known about the vegetable kingdom.

The story of 'feminine' botany has had its focus in England. Because Shteir's volume again highlights England, we still do not know whether this is a uniquely British phenomenon or characteristic of botany throughout Europe, the Americas and other parts of the world. Natural theology, the attempt to derive the existence of God from empirical facts, was especially strong in England, which perhaps strengthened the appeal of botany to women there.

Shteir discusses in depth the many aspects of women's work in mainstream botany. But she does not discuss conflicts between what came to be recognized as mainstream botany and women's traditional areas of knowledge, such as herbal medicines. The rise of male experts among midwives, later called gynaecologists, sounded the death-knell of knowledge on contraceptives and abortifacients (mostly herbal in nature) - knowledge traditionally belonging to women.

When women were moved out of botany, the consequences went well beyond the loss of livelihoods or opportunities - entire areas of expertise were lost or submerged.

In Cultivating Women, Cultivating Science, Shteir weaves intriguing biographies of women botanists into her intricate account of Victorian culture, science and society. This elegant book is essential reading for anyone interested in plants and science.

Londa Schiebinger is in the Department of History, Pennsylvania State University, University Park, Pennsylvania 16802, USA.

\title{
Imitating nature's designs
}

\author{
Robert W. Cahn
}

Biomimetic Materials Chemistry. Edited by Stephen Mann. VCH: 1996. Pp. 383. DM 189, \$125, £76.

'BIOMIMETIC' is a new word that has not yet made it into the Oxford English Dictionary. It refers to a novel concept, essentially a creation of the 1990s: the imitation of natural design. 'Biosynthesis' is a related term, meaning the imitation of chemical processes found in nature in order to synthesize materials that may not themselves be found in nature. In 1993, Paul Calvert, one of the contributors to this volume, listed some reasons, as they appeared then, for focusing researchers' interest on biological routes to polymeric materials: possible future oil shortages; promoting fermentation methods for making plastics and fibres from starch-derived feedstocks; increased demand for biodegradable plastics; and the rapid development of genetic engineering, permitting synthesis of proteins (and perhaps polysaccharides) by bacterial routes. He went on to cite some reasons for looking at natural biomaterials as inspiration for solving problems relating to load-bearing composites and ceramics. Since Calvert compiled his list, several journals in this field have been launched.

It is important to make distinctions. There is a thriving branch of sciencebased engineering devoted to the design of materials for medical purposes, such as bone prostheses, heart valves, replacement eye lenses and artificial blood vessels. As I write this, the proceedings of the Sixth International Symposium on Bioceramics (that is, ceramics for medicine, as distinct from ceramics made by biological organisms) have just been published. So medical engineering is already a mature field. In the book reviewed here, however, the emphasis is on ways of making, or designing, materials by approaches borrowed from the biological world. Most of these materials are not intended for medical applications. Both biosynthesis and biomimetics form the subject-matter of the book, although only the latter term appears in the title. This complex of approaches derives from much earlier research on biochemistry and on the mechanical properties of natural materials, especially fibres, tendons, bone and exoskeletons.

The book's 22 authors contribute 13 chapters, most of which fall neatly into two classes. There are four chapters on the biosynthesis and biomimetics of ceramics and organic-ceramic composites. They are all written by people who would be content to be described as materials scientists, and there is a strong emphasis on achieving products with desirable properties, especially mechanical strength and toughness: these chapters are primarily about biomimetics. Six chapters have a much more strongly chemical flavour and concentrate more on biosynthesis than biomimetics. They include topics such as templatedirected nucleation of inorganic materials, 'biogenic' cadmium sulphide semiconductors (by way of phytochelatins) and those fashionable entities, nanostructures. The two groups of papers mostly pursue different approaches, but there are certain areas of overlap, notably the topic of inorganic structural materials in organisms, singlecrystal exoskeletons in particular, and a focus on the mechanisms by which, for instance, single-crystal exoskeletons (as in some diatoms) can come into existence.

Finally, there are three unclassifiable chapters: one a fascinating chapter on using the venerable Langmuir-Blodgett technique to make organized films of minute particles (two-dimensional crystals, as it were) by flotation on a liquid surface and then transferring these to a solid substrate; another, an extraordinary account of bacterial fibres and mineralized products made from them. It seems that bacterial cells under certain circumstances can aggregate one-dimensionally to form 'ropes' of considerable strength. These ropes are solutions still looking for problems, as lasers once were. Then there is a fine chapter on the application of self-assembled two-dimensional protein lattices to generate nanocrystalline inorganic lattices by a process here imaginatively entitled "parallel nanometer molecular lithography".

The chemically focused chapters are not easy reading for a materials scientist. They are full of jargon, and no attempt is made to temper the wind to the shorn lamb. This is particularly true of the introductory chapter by the editor (clearly a man with great influence in the whole field). I am driven to the conclusion that the book is intended by its editor for chemically sophisticated readers only, and this is reinforced by the fact that the materials science chapters are concentrated at the rear of the book. By contrast, Calvert's chapter on "Biomimetic inorganic-organic composites" has virtually no jargon of any kind, focuses on actual and possible uses, and reviews the whole field of ceramics and composites in a broad and balanced manner. I am well aware that in making these critical comments I may be doing nothing more than revealing my own lack of chemical expertise, but it remains true that the chapters with an approach like Calvert's are better written.

Despite the severe incidence of highly technical chemistry, a good deal of this book will be accessible and valuable to materials scientists (including ceramists), as well as to chemists intent on novel approaches to synthesis. The book is a pioneering effort, especially in its combined attention to both biosynthesis and biomimetics, and as such is to be welcomed.

Robert W. Cahn is in the Department of Materials Science and Metallurgy, University of Cambridge, Pembroke Street, Cambridge CB2 $3 Q Z$, UK. 